Arab World English Journal (AWEJ) Volume 12. Number1 March 2021

Pp. $40-58$

DOI: https://dx.doi.org/10.24093/awej/vol12no1.4

\title{
Using Parallel Corpora in the Translation Classroom: Moving towards a Corpus-driven Pedagogy for Omani Translation Major Students
}

Awad Alhassan

Department of English Language and Literature, College of Arts and Applied Sciences,

Dhofar University, Salalah, Oman

Corrspondent Author: awad_alhassan@hotmail.com

Yasser Muhammad Naguib Sabtan

Department of English Language and Literature, College of Arts and Applied Sciences,

Dhofar University, Salalah, Oman

\&

Department of English, Faculty of Languages and Translation

Al-Azhar University, Cairo, Egypt

Lamis Omar

Department of English Language and Literature, College of Arts and Applied Sciences

Dhofar University, Salalah, Oman

Received: $12 / 29 / 2020$

Accepted: 1/30/2021

Published:3/24/2021

\section{Abstract}

Research has shown that parallel corpora have potential benefits for translator training and education. Most of the current available Arabic corpora, modern standard or dialectical, are monolingual in nature and there is an apparent lack in the Arabic-English parallel corpora for translation classroom. The present study was aimed to investigate the translation problems encountered by Omani translation major students when translating from Arabic into English with a view to proposing some corpus-informed pedagogy approach for training student translators to overcome these challenges by looking at some model samples of professional translation. Thirty students voluntarily took part in the investigation. The study adopted a combination of both corpus and qualitative methodology whereby some typical problems students would encounter when translating from Arabic-into-English were selected along with some specific Arabic texts involving these problems were prepared and the participants were asked to translate them into English. The participants were provided with some samples of the parallel English translated texts and were asked to compare and contrast their translations with these samples and reflect on the overall experience. They were then interviewed to explore their impressions about and the extent to which they think that parallel corpora would help them improve their translation. Results of data analysis indicated that the participants experienced several translation challenges. They, however, showed an overall positive attitude towards parallel Arabic-English corpora as they reportedly found them very helpful in improving their translation. Pedagogical implications for corpus-informed translation teaching, training and materials design and development are presented and discussed.

Keywords: Arabic-English translation, Omani translation major students, parallel corpora, translation challenges, translation classroom, translator education

Cite as: Alhassan, A., Sabtan,Y.M.N., \& Omar, L. (2021). Using Parallel Corpora in the Translation Classroom: Moving towards a Corpus-driven Pedagogy for Omani Translation Major Students. Arab World English Journal, 12 (1) 40- 58 . DOI: https://dx.doi.org/10.24093/awej/vol12no1.4 
Arab World English Journal (AWEJ) Volume 12. Number 1. March 2021

\section{Introduction}

Recent developments in corpus linguistics have provided a range of implications for language research and pedagogy (Kennedy, 2014). The building and designing of large computer-processed corpora have provided many pedagogical opportunities for translation teaching and the translator education and professional development. Research on corpora in translation (e.g., Alhassan, 2015; Baker, 1993; Baker, 1995; Bernardini, 2004; Bernardini, Stewart, \& Zanettin, 2003; Fantinuoli \& Zanettin, 2015; Frankenberg-Garcia, 2005; Olohan, 2004; Varantola, 2003) has shown potential benefits for parallel corpora bi-or multilingual in the translation classrooms. Teachers can use such corpora in the classroom to expose students to a range of parallel texts involving instances from both source and target languages. This could help students raise their awareness and enhance their translation skills by studying and reflecting on how professional translators would achieve various types of translation (Alhassan, 2015). Corpora, particularly the monolingual, such as the British National Corpus (BNC) have already been well in use in the language teaching and learning classroom (Biber, Conrad \& Reppen, 1998; Gabrielatos, 2005; Sinclair, 2004). Language teachers use target language monolingual corpora to expose students to various patterns of the target language and to encourage them to explore, observe and notice how the target language is authentically used by native speakers. This would in turn help learners to strengthen their autonomy and become more explorative and independent learners. However, the use of corpora seems scarce in the translation classrooms. Put simply, we need to know the extent to which corpora can be used in the translation classroom and the benefits and challenges on the side of both translation teachers and students. We, therefore, need more empirical research to systematically explore the use of parallel corpora in the translation classroom. More specifically, we need more studies to explore the use of parallel Arabic-English-Arabic corpora in relation to student translators' education and training. While we have some scattered attempts to build Arabic monolingual corpora for Arabic language teaching and research, we do not seem to have attempts to build and systematise Arabic-English parallel corpora for translation teaching and research. We also need more research not only to introduce corpora in the translation classroom but also to explore students' attitudes, benefits, challenges and their overall experience with the use of corpora in their translation learning and training process.

The present study duly strives to contribute to the research that is intended to fill this gap. The overarching objective of the study is twofold. It tries to investigate and map out the translation students' various challenges when translating from the source (Arabic) language to the target (English) language. It also attempts to explore the potential use of parallel corpora in training students to overcome such challenges.

The study was conducted in an Omani private higher education context where a translation major is offered as stand-alone speciality. Corpora were not used in this context as part of the translation curriculum nor are they used by teachers as ad hoc supplementary materials. The significance of the present study stems from the fact that it is the first of its kind in Oman as to the best of our knowledge there has no research thus far been conducted on this topic in this particular context. The study, as mentioned earlier, will also have a significant contribution to the advancement of research in corpus linguistics and use of corpora in translation and translator education in its ecological context and beyond. Given this backdrop, the present study strives to address the following research questions: 
Arab World English Journal (AWEJ) Volume 12. Number 1. March 2021

1. What problems and challenges do Omani translation major students experience when translating from Arabic into English?

2. How can parallel corpora help them overcome these challenges and problems?

3. How do they view the relevance of parallel corpora to their translation training and education?

\section{Literature Review}

\section{Translation Challenges}

Despite the recent advancements in translation as an academic discipline and professional activity going in tandem with the continuous progress of the technological revolution, a myriad of translation issues in any language combination still pose challenges for human translators and machine translation software alike. Certainly, the technological revolution has left an everlasting positive impact on Translation Studies (O'Hagan, 2019) just like it did on any other field of knowledge, yet impediments that translators encounter, regardless of their academic and professional background and experience, continue to pose a threat to the success of translation processes. In fact, it was the need to discuss translation issues and address them that triggered the academic interest in translation as an independent discipline.

Translators spot different types of problems while looking for 'equivalences' between a Source Language (SL) and a Target Language (TL). The concept of 'equivalence' was introduced to Translation Studies (TS) by Jakobson (1959), and then it was elaborated by scholars like Nida (1964), Nida and Taber (1982), Baker (2018) and others (see Kenny, 2008). Nida (1964) and Nida and Taber (1982) elaborated on the concepts of formal equivalence and dynamic equivalence (cultural equivalence). Bell (1991) distinguished two types of equivalence: semantic equivalence and stylistic equivalence. Baker (2018) discussed "translation problems arising from the lack of equivalence at the level of the word and beyond the level of the word in relation to collocation, idioms and fixed expressions" (Baker, 1992, as cited in Lahlali \& Abu Hatab, 2014, p. 109).

Apart from the unpublished MA and $\mathrm{PhD}$ research on translation problems, studies on the challenges of translation in Arabic-Englishlanguage pair seem to be scarce and only appear in guidebooks with some translated examples accompanied by some translation strategies (Almanna, 2016; Almanna, 2018; Dickins, Hervey \& Higgins, 2017; Lahlali \& Abu Hatab, 2014). For instance, Almanna (2016) provided a manual coursebook on annotating translation strategies in texts translated between English and Arabic. In the same vein, Lahlali and Abu Hatab (2014) dealt with samples translated between English and Arabic in different text types including literary texts, economic texts, scientific texts, media texts, administrative texts as well as legal texts with a limited academic discussion of the sources and natures of the problems of translation between these two languages.

Additionally, Dickins et al. (2017) explored diverse translation problems on the lexical, linguistic, stylistic, conceptual, as well as dialectical levels. The authors also tackled far-reaching problems that originate beyond the source text (ST) such as intertextual components and "genrerelated problems in translating between the two languages" (p. 187), focusing mainly on the translation of technical texts and pointing out that "lexical problems" that originate in translating 
technical texts as a result of a gap in the knowledge of the translator are "the most dangerous" (p. 234), as explained inthe following passage:

"conceptual problems are the most intractable of all those that face the technical translator. Non-specialists are always likely to reach a conceptual impasse from which no amount of attention to syntax or vocabulary can rescue them. In that case, they have only two options: to learn the concepts of the field in which they wish to translate or to work in close consultation with experts. In practice, trainee translators generally do both of these, quickly becoming experts themselves with the help of specialist supervisors." ( $p$. 238)

At the heart of the concept of equivalence in TS lies the concept of meaning (Krzeszowski, 2012; Van Leuven-Zwart, 1990) as languages differ in the meanings they assign to different lexical items, hence the issue of non-equivalence. According to translation theories, the point of departure in identifying translation problems happens to be 'meaning'. The concept of meaning is wider than to be covered in a single study on meaning-related problems of translation, yet it is considered to be the benchmark against which one can measure how far the translation has succeeded in representing the original. When a translation is evaluated by a publishing house, client, reader, or instructor, it tends to be judged vis-à-vis the effectiveness of the target text (TT) in communicating the meanings of the ST. Baker (2018) reviewed scholarly research on the concept of meaning to use it as a foundation for an elaborate discussion of translation problems with a special reference to translation between English and Arabic. Baker (2018) suggested four levels of meaning that a lexical item might have: "propositional meaning, expressive meaning, presupposed meaning and evoked meaning" (p. 12).

In principle, a word has a direct meaning which is called lexical or denotative meaning (Murphy, 2010; Dickins et al., 2017) and which also corresponds to dictionary meaning. The main problem with denotative meaning is that it is polysemous (Riemer, 2005), which leads to some translation issues and accentuates the importance of exploring deeper levels of meaning when translating or examining a translation. The first level of meaning which was discussed by some linguists and translation scholars in relation to translation problems is propositional meaning. According to Baker (2018), propositional meaning embodies the relation between a lexical item and what it actually describes when used in a certain context (real or imaginary context). This level of meaning is the key to selecting one of the different senses that a word/lexical unit has in the lexicon, which is why it can be considered as the borderline between right or wrong in judging a translation work. Baker (2018) stated that "When a translation is described as 'inaccurate', it is often the propositional meaning that is being called into question" (p. 12). In other words, propositional meaning can be considered as a yardstick for judging the correctness or incorrectness of a translated item since it is the minimum level that needs to be satisfied to disambiguate the basic level of meaning. Without observing this level of meaning, a translator risks producing a meaningless or incongruous TT. Normally, translation problems related to propositional meaning are less common compared to problems encountered by translators in processing more advanced levels of meaning simply because there are always cues that disambiguate the subtle differences between the different senses/denotations of a word. 
The second level of meaning to be discussed in this account is presupposed meaning. From the perspective of a translation process, presupposed meaning can be considered second important to propositional meaning. Baker (2018) defined presupposed meaning as a type of meaning which "arises from co-occurrence restrictions, that is restrictions on what other words or expressions we expect to see before or after a particular lexical unit" (p. 13). An example of presupposed meaning is "Collocational restrictions" which are defined as "semantically arbitrary restrictions which do not follow logically from the propositional meaning of a word" (Baker, 2018 , p. 14). The main issue with presupposed meaning is how it influences the naturalness of a lexical item in a certain linguistic system. Accordingly, a misrepresentation of presupposed meaning does not infringe on the basic level of meaning (the propositional meaning). Rather, it leaves an impact on how well-received the end result of the translation process is by the readers/recipients.

This problem becomes prominent when a translator uses the technique of calque in translating collocations or similar lexical sequences and patterns (Vinay \& Darbelnet, 1995). Calque is a translation technique which involves borrowing a certain sequence and translating it literally, in which case the result will be intelligible for the reader, but at the same time it may impress the translator as unnatural or "awkward" (Vinay \& Darbelnet, 1995, p. 33). Newman and Husni (2015) discussed presupposed meaning under their account on phraseology in which they dealt with lexical sequences such as collocations, compounds and idiomatic expressions. According to Newman and Husni (2015), collocations:

"occupy the biggest field in terms of number and incidence, and are thus most often encountered by the translator and language-learner alike, to whom they pose a formidable obstacle. Correct use of collocations... is one of the key features of idiomatic, i.e., natural native, language use" (p. 1).

The third level of meaning, a source of greater challenges for both professional and student translators, is connotative or expressive meaning. Like presupposed meaning, "Expressive meaning cannot be judged as true or false. This is because it relates to the speaker's feelings or attitudes rather than to what words and utterances refer to" (Baker, 2018, p. 12). The fourth level of meaning discussed by Baker is evoked meaning which "arises from dialect and register variation...within a specific community or groups of speakers" (p. 14). The last two levels of meaning are highly advanced and hardly noticed when discussing translation problems from a pedagogical perspective as they require a very strong command of both SL and TL. By and large, the first and second levels of meaning, propositional meaning and presupposed meaning, are given priority in judging on the quality of a translation as they are used as criteria to decide whether a translation is correct and/or natural or not, respectively. On the other hand, translation issues related to expressive meaning and evoked meaning are observed more clearly in advanced levels of translation as they are embedded and not communicated directly. In general, all four levels of meaning are a source of challenge for translating in any language combination. They would lead to different types of translation issues if the translator does not recognize any of them or fails to identify an appropriate strategy to deal with such issues. 


\section{Corpora in Translation and Translator Education}

The unprecedented progress in information technology gave birth to corpus-based studies which led to a paradigm shift in all disciplines including linguistics (Kennedy, 2014), and TS (e.g., Baker, 1993; Baker, 1995; Bernardini, 2004; Bernardini et al., 2003; Fantinuoli \& Zanettin, 2015; Frankenberg-Garcia, 2005; Olohan, 2004; Varantola, 2003). Corpora are principled and systematic collection of electronic texts which are analysed automatically or semiautomatically.). The use of corpora in TS is a relatively recent trend (Marco, 2019).

Originally, corpora were used in Machine Translation (MT) and building databases for scientific terminology (Baker, 1995). Baker (1995) developed a taxonomy that could be used in TS based on "the range of languages involved" (p. 230). Accordingly, the author introduced three types of corpora: parallel, multilingual and comparable corpora. A parallel corpus is a group of source texts aligned against their translated versions in the form of textual "stretches". Sabtan (2016) explained how parallel corpora became "a key resource as training data for statistical machine translation, and for building or extending bilingual lexicons and terminologies" (p. 318). Consequently, parallel corpora started to be used in several academic and educational activities including second language teaching and learning (e.g., Yahya, Alotaibi \& El-Dakhs), teaching translation as well as training translators in view of their value and applications for an empirical field like TS (Doval \& Nieto, 2019). Commenting on the pedagogical value of parallel corpora, Doval and Nieto (2019) stated:

"Even if their primary use is within linguistic and translation research, parallel corpora are also becoming increasingly present in foreign language and translation learning and teaching, providing plenty of translation suggestions through examples of real usage" ( $\mathrm{p}$. 4).

The second type of corpora discussed by Baker (1995) is the multilingual corpora which "refer to sets of two or more monolingual corpora in different languages, built up either in the same or different institutions on the basis of similar design criteria" (p. 232). Although this type of corpora can be used to train human and machine translators, they fall short of solving diverse translation problems as they are built on the assumption that there is always a way of expressing a certain point naturally, and multilingual corpora can illuminate translators about these natural ways of representing ideas in the TL, which is partially true and quite limiting. The third type of corpora is comparable corpora which fall in the middle between parallel and multilingual corpora. In comparable corpora there are "two separate collections of texts in the same language" (Baker, 1995, p. 234): one for SL texts and the other for TL texts. The SL collection is a corpus of monolingual texts that have been collected over a period of time, and the TL collection may comprise any available monolingual corpus in the TL "provided it is similar in design to the translation corpus" (Baker, 1995, p. 234). In other words, the monolingual texts used in the two sets of comparable corpora are "matched as far as possible in terms of text type, subject matter and communicative function" (Altenberg \& Granger, 2002, as cited in Hareide, 2019, p. 20).

Compared with multilingual corpora, parallel corpora provide several opportunities to professional and academic translation bodies/individuals as they have two functions "the first is descriptive and the second applied, whether parallel corpora are used by professional or trainee translators" (Marco, 2019, p. 43). One of the main applications of parallel corpora is to find fast 
and tested solutions to certain translation issues and to generally see how professional translators handle various translation problems. Marco (2019) succinctly explained the potential advantages of parallel corpora for translation:

"they provide a wealth of actual translation solutions at the touch of a button. The advantages of parallel corpora over bilingual dictionaries are obvious: the translation equivalents they offer have actually been used by someone (usually a professional translator) in a specific context, and there are as many of them as matches for a given query. Not for nothing are parallel corpora also known as translation corpora in the literature" (p. 40).

However, using parallel corpora in translation tasks has potential challenges. The main limitations are associated with the corpus design in terms of representativeness, typicality and size (Kennedy, 2014). Despite the exponential improvement in the quantity and quality of parallel corpora available electronically, they are still not popular as a tool in the translation process or L2 classroom for a number of reasons. First, there is a general assumption that the linguistic content of corpora is beyond the ability of learners to process or use effectively. Second, "even if the language were of an appropriate level, the tools for searching parallel corpora are not learner-friendly, as they are designed with researchers and not language learners in mind" (Doval \& Nieto, 2019, p. 10). Other issues include the lack of awareness about the importance and uses of corpora among instructors and the lack of tools available for accessing parallel corpora.

The most recent approaches to corpora as research and pedagogical tools, however, highlighted the importance of both parallel and comparable corpora in teaching translation and translation research. For example, Doval and Nieto (2019) remarked that both types of corpora "provide essential training data for statistical translation models, translation memories, or lexical and terminological extraction" (p. 3) and help trainers and researchers "observe decision-making processes performed by real translators" (p. 4). Alhassan (2015) maintained that the three types of corpora provide translation teachers and learners with "insights into dealing with and observing how and what strategies expert/professional translators adopt to overcome typical translation problems" (p. 34). According to Marco (2019), using a combination of "comparable and parallel corpora enables the researchers to triangulate and therefore to provide at least one kind of explanation for the patterns observed in comparable corpora" (p. 54).

The fact that parallel corpora is in the process of inevitable and imperative development in different language combinations becomes more protruding in language combinations that involve an electronically under-resourced language such as Arabic because originally there is an entrenched, palpable shortage of Arabic language digital corpus (Bakari, Bellot \& Neji, 2016; Saad \& Ashour, 2010), which reflects directly on parallel corpora available in Arabic and any other language. Therefore, translators and translation academics working in the English/Arabic language combination face significant challenges when it comes to the availability of parallel corpora, particularly so in the case of Arabic-English corpora. First and foremost, recent research suggests that the available resources are restricted both in scope and domain. Second, ArabicEnglish parallel corpora are not popular among translators, linguists and academics in the Arab world (Alhassan, 2015; Alotaibi, 2016; Alotaibi, 2017). 
There is a reported scarcity in Arabic parallel corpora for translation purposes. Moreover, Alotaibi (2016) pointed out the scarcity of Arabic English parallel corpora clarifying that "Arabic is a relatively under-resourced language when compared to English" (p. 1). The author attributed this lack of Arabic-English parallel corpora to their high cost in terms of time, money and the efforts needed to build them, refine them and update them continuously

Alotaibi (2017) provided a substantial review of "the value of integrating parallel corpora into translator training and their positive impact on translator's performance" (p. 325) while highlighting the lack of related studies that address this timely topic "in the Arab world and among Arabic translators" (p. 325). For instance, parallel corpora may unveil translation strategies used in dealing with certain translation issues in the lexical components of the translated text including synonymy, idioms, collocational patterns and other lexical sequences, not to mention their role in detecting various distinctive features in different text types such as syntactic features, semantic features, communicative features, etc.

Furthermore, Alhassan (2015) explored the use of parallel corpora for pedagogical purposes in the classroom focusing mainly on "Arabic into English translation tasks as the difficulty is relatively more when it comes to translation into the second language" (p. 32). The researcher explored the advantages associated with adopting an integrated approach to the use of monolingual corpora, parallel corpora as well as comparable corpora in "teaching translation from Arabic into English" (P. 33), underlining the challenges encountered by teachers and students alike throughout this practice.

Alhassan (2015) discussed interesting examples about the role of parallel corpora in unveiling contextual cues that can help students and teachers identify "the appropriate equivalent in the target language" (p. 37). On the other hand, the author explained how comparable corpora can be equally important in that it raises students' awareness about the communicative function of words by detecting differences in "comparable texts from Arabic and English that share the same kind of topic", particularly texts available on "Web and the media which cover the same topic, news story, extracted from two well-known Arabic and English channels" (p. 41).

Collecting corpora manually or electronically is a tedious process which requires sound background knowledge and professional experience about their uses and functions besides "a set of criteria for selecting and describing them" (Doval \& Nieto, 2019, p. 3). By and large, there is a noticeable shortage of research which is dedicated to investigating possible methods on collecting corpora for the purpose of pedagogical translation activities. Recent research on the topic underscored the significance of representativeness as an indispensable criterion that parallel corpora need to fulfil (Alhassan, 2015; Alotaibi, 2016; Alotaibi, 2017; Baker, 1995). According to Baker (1995), in order to guarantee that the collected corpus is representative it needs to have a clear purpose and fulfil certain criteria. This becomes even much more significant when collecting corpora for pedagogical purposes. Alotaibi (2016) listed the factors needed to build a quality parallel corpus project including representativeness, regular updating, as well as alignment (manually or automatically) at the phrase level, sentence level, and other levels. In fact, alignment is an indispensable component in collecting parallel corpora. Doval and Nieto (2019) confirmed that "alignment is a crucial task in the construction of parallel corpora and an initial step for any exploitation thereof" (p. 6). 
To sum up, there is no doubt that adopting a corpus-oriented approach to teaching translation in the classroom is a burdensome task as it requires the necessary background knowledge, both academically and professionally, the determination to invest in the scarce available resources as well as a robust methodology to identify the learners' cognitive and training needs, build a relevant corpus and know how to use it in a sound pedagogic manner.

\section{Methodology and Research Design}

The study used a combination of both corpus and qualitative methods to explore the potential of using parallel corpora for training student translators as to how they can better translate from the source language into the target language.

\section{Participants}

Thirty translation major students in the third year of their study at an Omani private university participated in the present study. All participants, who are native speakers of Arabic, were enrolled in a BA translation programme and the study data was collected during the academic year 2018-2019. Their English proficiency level ranges from intermediate to upper intermediate. They take several theoretical and practical courses in translation as part of their BA in Translation major. They have not been exposed to any corpus-based teaching and training in their study programme.

\section{Data Collection Procedures}

Based on our experience as translation teachers, the researchers first classified the various translation problems and also validated them from the literature that Omani translation major students typically face when translating from Arabic into English. They then selected and designed some specific Arabic texts that involved such challenges and asked our participants to translate them into English. The researchers, as translation instructors, translated the selected Arabic texts into English and showed them to the students immediately after they had finished their translation of the Arabic texts. The participants were then asked to compare and contrast their translation with the English translated texts in the parallel corpus and reflect on the experience. They were then interviewed (open-ended written format) to explore their impressions about and the extent to which they think that the parallel corpus could help them improve their translation skills.

\section{Data Analysis}

After collecting the data from the participants in the first phase (the translation of Arabic texts into English) and the second phase (the semi-structured interviews in written format), the researchers then examined the students' translations as well as their opinions and reflections on the potential benefits of the parallel corpus in helping them to deal with the challenges they encounter and thus improving their translation skills. The translation problems were classified based on Baker's (2018) model of translation equivalence in relation to the study first research question. As for the second part relating to the retrospective interviews, the students' responses were coded thematically and inductively and the most representative themes were incorporated in the analysis with regard to the second and third research questions. 


\section{Results and Discussion}

This section presents and discusses the findings of the study with the relevant literature. The first part is devoted to the translation problems and the second part focuses on the participants' views, reflections and experiences with the use of corpora in translator training and education.

\section{Translation Problems}

Participants have encountered a number of both lexical and grammatical problems in their English translations of the Arabic sentences that were given to them. The lexical problems will be presented and discussed first and will be followed by the presentation and discussion of grammatical problems.

\section{Lexical Problems}

The lexical problems can be classified into a number of types.

Calque

Participants have been found to use calque in rendering some Arabic lexical items into English. These are words or word combinations. The following table sheds light on this specific translation problem in a number of examples translated by the participants. The words that have been translated using calque are underlined within the SL sentences as well as the students' translation and the TL parallel translation that was given later to students to reflect on their translation.

Table 1. Calque translation problems

\begin{tabular}{|c|c|c|}
\hline SL words & Students' Translation & Parallel Translation \\
\hline بقر كبير من اهتمام الدولة. النثية & $\begin{array}{l}\text { Fish wealth has received a great } \\
\text { deal of state attention. }\end{array}$ & $\begin{array}{l}\text { Fisheries have received much } \\
\text { support from the state }\end{array}$ \\
\hline 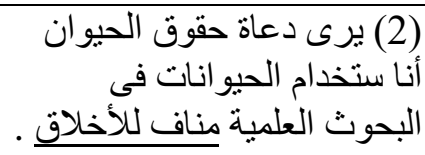 & $\begin{array}{l}\text { Animal rights activists see that } \\
\text { animal research is contrary to } \\
\text { morality }\end{array}$ & $\begin{array}{l}\text { Animal rights activists believe } \\
\text { that using animals as research } \\
\text { subjects is immoral. }\end{array}$ \\
\hline
\end{tabular}

It is apparent that some students used calque to render the underlined Arabic words, translating literally each part of it into English and thus failed to produce an accurate translation for each one of them. The first example is the word combination الثروة السمكية. It has been found that many students translated it as "fish wealth" while it is normally translated as" fisheries". In fact, other students gave different inaccurate translations, but this one given here has the highest percentage among the students' inaccurate translations. It is worth noting that many participants provided the accurate equivalent for the phrase in question. Finally, the phrase مناف للأخلاق is translated literally as "contrary to morality", as students translated the negative adjective word for word, while it has an equivalent negative adjective "immoral".

\section{Problems with Propositional Meaning}

Some students failed to give the appropriate contextual sense of some words in the example sentences. This is illustrated in table two below. 
Arab World English Journal (AWEJ) Volume 12. Number 1. March 2021

Using Parallel Corpora in the Translation Classroom

Alhassan Sabtan \& Omar

Table 2. Propositional meaning problems

\begin{tabular}{|c|c|c|}
\hline SL words & Students' Translation & Parallel Translation \\
\hline 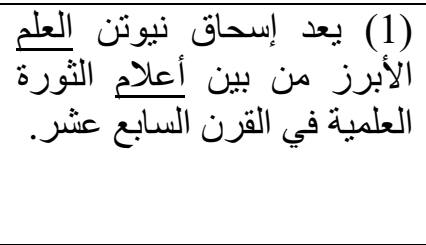 & $\begin{array}{l}\text { Isaac Newton is the most } \\
\text { prominent science among the } \\
\text { flags of the scientific } \\
\text { revolution in the seventeenth } \\
\text { century. }\end{array}$ & $\begin{array}{l}\text { Sir Isaac Newton was the most } \\
\text { prominent figure of the scientific } \\
\text { revolution in the seventeenth } \\
\text { century. }\end{array}$ \\
\hline هو من اكتشف قانفيزئي و الرياضية الجياذية. & $\begin{array}{l}\text { This is physician and } \\
\text { mathematician who discovered } \\
\text { the law of attraction. }\end{array}$ & $\begin{array}{l}\text { He was a physicist and } \\
\text { mathematician, who discovered } \\
\text { the law of gravitation. }\end{array}$ \\
\hline
\end{tabular}

As can be noticed, the students made mistakes in translating the Arabic words ando علم and "جاذبية ind English. The two words have been translated inaccurately as "science" and "attraction". The appropriate equivalents are "prominent figure" and "gravitation" respectively. The Arabic word is described as a homograph. According to Jackson (1988), a homograph is a word that has the same spelling form but different pronunciation and meaning. In fact, the modern form of Arabic, which is normally referred to as Modern Standard Arabic (MSA), is full of homographs, as words written in MSA are undiacritized and so have different senses. Thus, the current word على can be diacritized to mean "science", which is not meant here, or be diacritized in another way to mean either "flag" or "prominent figure". In fact, this is a case of polysemy where the word with the same spelling and pronunciation has two different senses or meanings; the first sense is the one wrongly rendered by the students as "flags" in the translation of the plural form أعلام and the other one, which is meant here, is the plural of the word "prominent figure". The students interpreted the word عل as referring to the sense of "science", while it refers to the sense of "prominent figure". As for the word جاذبية, it has two senses, the first one, which was chosen by the students, is "attraction" and the other one which is the right equivalent in the current example is "gravitation" or "gravity".

In fact, a word that is polysemous, i.e., having more than one sense, most often causes problems for student translators, as shown in the previous examples. The problem of not conveying the right equivalent for one of the senses of a SL word is very common. This has to do with the propositional meaning of a word, as stated by Baker (2018) or denotative meaning as used by Dickins et al., 2017). Propositional meaning, according to Baker (2018) embodies the relation between a lexical item and what it actually refers to when used in a real or imaginary context.

\section{Problems with Presupposed Meaning}

This part deals with the problems encountered by the participants in translating the presupposed meaning which, according to Baker (2018), arises from co-occurrence restrictions. One type of these restrictions is the collocational restrictions. The students in the current study faced difficulties in giving the right English collocations for some Arabic collocations, as shown in table three. 
Arab World English Journal (AWEJ) Volume 12. Number 1. March 2021

Using Parallel Corpora in the Translation Classroom

Alhassan Sabtan \& Omar

Table 3. Presupposed meaning problems

\begin{tabular}{|c|c|c|}
\hline SL words & Students' Translation & Parallel Translation \\
\hline الأمريكية & $\begin{array}{l}\text { Some transcontinental } \\
\text { companies cut American goods. }\end{array}$ & $\begin{array}{l}\text { Some multinational } \\
\text { corporations have boycotted } \\
\text { the American goods. }\end{array}$ \\
\hline 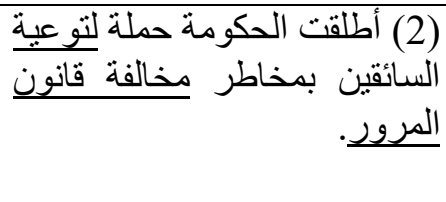 & $\begin{array}{l}\text { The government has launched a } \\
\text { campaign to educate drivers } \\
\text { about traffic violation risks. }\end{array}$ & $\begin{array}{l}\text { The government has launched } \\
\text { a campaign to raise drivers' } \\
\text { awareness of the dangers of } \\
\text { breaking the traffic rules. }\end{array}$ \\
\hline
\end{tabular}

As can be noticed, the SL Arabic collocation يقاطع بضاعة was inaccurately translated by the students as "cut goods", while it has the TL equivalent collocation "boycott goods". Similarly, the collocation يخالف قانون المرور is inappropriately translated by the students as "traffic violation" while it has the English collocation "break traffic rule/law". However, the students managed to accurately translate the SL collocation يطلق حملة into the target language as "launch a campaign"

\section{Problems with Expressive or Connotative Meaning}

Some words have connotative or expressive meaning which is not conveyed by the students in their translation. This produces inaccurate equivalents of SL words, as shown in the following table.

Table 4. Expressive meaning problems

\begin{tabular}{|c|c|c|}
\hline SL words & Students' Translation & Parallel Translation \\
\hline الحكو مة بالفساد و المحسوبية المعارضة & $\begin{array}{l}\text { Opposition forces accused the } \\
\text { government of corruption and } \\
\text { nepotism. }\end{array}$ & $\begin{array}{l}\text { Opposition forces accused the } \\
\text { regime of corruption and } \\
\text { nepotism. }\end{array}$ \\
\hline 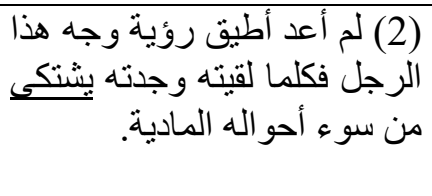 & $\begin{array}{l}\text { I can no longer see the face of } \\
\text { this man. Whenever I find him } \\
\text { he complain about his poor } \\
\text { financial conditions. }\end{array}$ & $\begin{array}{l}\text { I can no longer stand this man } \\
\text { as whenever I meet him I find } \\
\text { him whinging about his worse } \\
\text { financial circumstances }\end{array}$ \\
\hline
\end{tabular}

In the first example, the word "الحكومة" is used in the negative context, since the words "accuse", "corruption" and "nepotism" create a negative contextual environment and so the accurate translation would be "regime". In another context, the word "الحكومة" has been accurately translated by the students as "government" since it is used in a positive context. This is a case of semantic prosody (Alhassan, 2015). As for the second example, the word "يشتكي" can be used in its propositional or expressive meaning.

\section{Grammatical Problems}

The following table presents a range of grammatical problems that have been observed in the students' translation. 
Arab World English Journal (AWEJ) Volume 12. Number 1. March 2021

Using Parallel Corpora in the Translation Classroom

Alhassan Sabtan \& Omar

Table 5. Grammatical problems

\begin{tabular}{|c|c|c|c|}
\hline SL words & Students' Translation & Parallel Translation & $\begin{array}{l}\text { Type of Grammatical } \\
\text { Error }\end{array}$ \\
\hline بقدر كبير من اهتمام الدولة. الثروة السمكية & $\begin{array}{l}\text { The fishery have a huge care } \\
\text { from the country. }\end{array}$ & $\begin{array}{l}\text { Fisheries have received } \\
\text { much support from the } \\
\text { state. }\end{array}$ & Subject-Verb Agreement \\
\hline 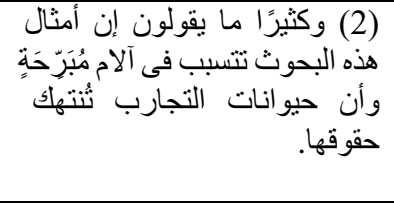 & $\begin{array}{l}\text { A lot of them say that } \\
\text { researches cause a lot of pain } \\
\text { for animals that violate their } \\
\text { rights. }\end{array}$ & $\begin{array}{l}\text { They often assert that the } \\
\text { experiments that are run } \\
\text { on animals cause severe } \\
\text { pain which is a violation } \\
\text { for animal rights. }\end{array}$ & Relative Clause \\
\hline 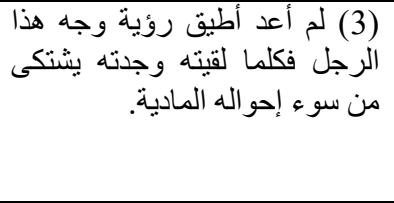 & $\begin{array}{l}\text { I can no longer see the face of } \\
\text { this man. Whenever I meet } \\
\text { him I find him complains } \\
\text { about his poor financial } \\
\text { conditions }\end{array}$ & $\begin{array}{l}\text { I can no longer stand this } \\
\text { man as whenever I meet } \\
\text { him I find him whinging } \\
\text { about his worse financial } \\
\text { circumstances }\end{array}$ & Verb Form \\
\hline 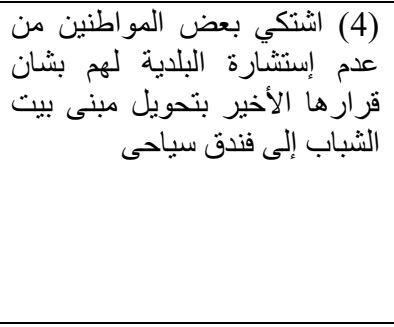 & $\begin{array}{l}\text { Some people are complaining } \\
\text { of not consulting with the } \\
\text { municipality the last decision } \\
\text { to transfer youth hostel to a } \\
\text { tourist hotel. }\end{array}$ & $\begin{array}{l}\text { Some citizens } \\
\text { complained that the } \\
\text { municipality had not } \\
\text { consulted them in its } \\
\text { recent decision of } \\
\text { transferring the youth } \\
\text { hostel into a tourist } \\
\text { hotel. }\end{array}$ & $\begin{array}{l}\text { (1) Tense } \\
\text { (2) Verb Complement }\end{array}$ \\
\hline 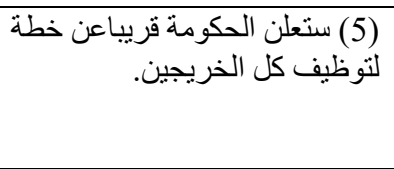 & $\begin{array}{l}\text { The government will } \\
\text { announce about a plan to } \\
\text { employment all graduates. }\end{array}$ & $\begin{array}{l}\text { The government will } \\
\text { soon announce its plan } \\
\text { for employing all } \\
\text { graduates. }\end{array}$ & $\begin{array}{l}\text { (1) Preposition } \\
\text { (2) Part-of-Speech }\end{array}$ \\
\hline 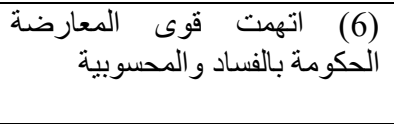 & $\begin{array}{l}\text { The opposition forces accused } \\
\text { the government } \underline{\text { with }} \\
\text { corruption and nepotism }\end{array}$ & $\begin{array}{l}\text { Opposition forces } \\
\text { accused the regime of } \\
\text { corruption and nepotism. }\end{array}$ & Preposition \\
\hline
\end{tabular}

In the first example of the grammatical errors, it can be noticed that the noun "fishery" is used in the singular form and is followed by the verb "have" and so the noun must be in the plural form to be in agreement with the verb "have". This is referred to as "subject-verb" agreement. In example two the underlined relative clause "that violate their rights" is wrongly used here as it refers back to animals which is not meant here. The SL relative clause actually refers to the "experiments conducted on animals" and not to "animals" themselves. As for example three, the verb form for "complain" is wrongly used as "complains" in the third person singular form. It can be used in the current context as "complaining or "complain". In example four there are two errors; the first is concerned with the use of the wrong tense where the verb in the SL sentence is in the past tense and the verb is used in the continuous present tense in the student translation. The second error is about the wrong use of the verb complement, which gives a wrong meaning of the SL sentence. In fact, the meaning of the SL sentence indicates that some citizens complained that they were not consulted by the municipality about its recent decision. The student translation, on the other hand, inaccurately means that some citizens complain that they (themselves) have not consulted with the municipality about its recent decision, which is not the right meaning. Example five shows two types of error; the first one is about the unnecessary insertion of the preposition 'about' between the verb "announce" and the object "plan". The second error is about the wrong use of the part-of-speech, where the noun 'employment' is wrongly used in place of the verb 'employ'. The final example includes a case of wrong use of 
Arab World English Journal (AWEJ) Volume 12. Number 1. March 2021

preposition. In the student translation the verb 'accuse' is wrongly followed by the preposition 'with', whereas the right preposition after this verb is 'of'.

\section{Students' Experience with the Parallel Corpus}

Participants were asked to reflect on the errors they made in their translation and compare between their translation and the parallel translation. The students were asked whether there were differences between their translation and the reference translation in the corpus. Most students indicated that there were differences between their translation and the translation in the corpus, specifically with regard to the sentences they had translated inaccurately as discussed above. They pointed out that they had problems in both vocabulary and grammar, with most of them expressing their opinion that the differences between their translation and the reference translation were basically concerned with vocabulary, whereas other participants indicated that the differences were related to grammar. It is worth noting that students' responses were elicited in Arabic and the relevant extracted examples used in the analysis were translated into English by the researchers. Below are some representative samples of the participants' responses:

Table 6. Students' responses about the difference between their own translation and the parallel translation

\begin{tabular}{|l|l|}
\hline 1 & There are many differences in the vocabulary. \\
\hline 2 & There are differences in sentence structure, grammar, and word order. \\
\hline 3 & Differences in use of terms and lexical choice (words in context) \\
\hline 4 & I found difficulty in translating long sentences. \\
\hline 5 & Reference translation uses some formal words while I used some informal words. \\
\hline
\end{tabular}

All participants pointed out that the parallel translations they were given were useful and helpful, as they helped them to identify their errors so that they could avoid them in the future. Below are further samples of the students' responses about the usefulness of the parallel corpus.

Table 7. Samples of the students' views about the parallel corpus

\begin{tabular}{|l|l|}
\hline 1 & $\begin{array}{l}\text { It was a great and useful experience, especially that most students find difficulty in translating } \\
\text { sentences from Arabic into English because it is not our native language. So, we make many } \\
\text { mistakes and I think that such experiences helped us learn how to avoid our mistakes in the } \\
\text { future. }\end{array}$ \\
\hline 2 & $\begin{array}{l}\text { The parallel corpus helped me a lot to understand translation in a simplified way. } \\
\text { mistakes so as to avoid them in the future. }\end{array}$ \\
\hline 3 & One should not translate word by word. They should look at the context of the whole sentence. \\
\hline 5 & It was good. It provided us with some new terms. \\
\hline 6 & It guided me to avoid literal translation in the future. \\
\hline 7 & $\begin{array}{l}\text { The list helped me to translate in a better way, because I face difficulty in translating from } \\
\text { Arabic into English and this list showed me how to translate from Arabic into English. }\end{array}$ \\
\hline 8 & It helped me to recognize the appropriate way to translate some complex sentences. \\
\hline 9 & It helped me to identify my mistakes so as to avoid them in the future. \\
\hline 10 & $\begin{array}{l}\text { I need to improve my vocabulary because it is more useful to know more about the text to be } \\
\text { translated. }\end{array}$ \\
\hline 11 & $\begin{array}{l}\text { I learned a lot from the list to avoid my mistakes. The list also helped me to discover my } \\
\text { weaknesses and this will help me as well as other students to develop our translation skills. }\end{array}$ \\
\hline 12 & I feel comfortable to see this list because it gives me a positive impression about translation. \\
\hline 13 & It was a good experience. \\
\hline
\end{tabular}


It is clear that the participants showed an overall positive attitude towards the parallel Arabic-English corpora and they reportedly found them very helpful and promising in improving their translation. The students were finally asked what they would do if they were given the chance to translate the same texts again after being exposed to the parallel translation. Below are samples of their responses:

Table 8. Students' views on their future translation strategies following their experience with the parallel corpus

\begin{tabular}{|l|l|}
\hline 1 & I will avoid literal translation and will take care of grammar \\
\hline 2 & $\begin{array}{l}\text { After looking at the parallel texts I will totally change my translation and try to make it better } \\
\text { and work on the long words and complex sentences. }\end{array}$ \\
\hline 3 & $\begin{array}{l}\text { I will try to avoid the mistakes I made, especially in grammar, as I made many grammatical } \\
\text { mistakes. }\end{array}$ \\
\hline 4 & $\begin{array}{l}\text { I will correct my mistakes and use words appropriately in their context and consider also word } \\
\text { order. }\end{array}$ \\
\hline 5 & $\begin{array}{l}\text { I would change the way I translated because Arab students normally use literal translation when } \\
\text { translating from Arabic into English. }\end{array}$ \\
\hline
\end{tabular}

It should be noted that corpora have been used in translation training in the classroom in different European language pairs and the translation quality has reportedly improved after using these resources (Bowker, 1998; Gallego-Hernández, 2015; Varantola, 2003; Zanettin 2002). However, there are scarce studies on exploring the usefulness of using corpora in training Arab student translators on how to translate well from their native Arabic language to English. Alotaibi $(2016,2017)$ are one of those few studies in the Arabic-English language pair. Alotaibi (2017) described a project at King Saud University to compile a 10-million Arabic-English parallel corpus to be used as a resource for language teaching and translation training. It was stated that the parallel corpus was intended to be used as a resource in translation training and language teaching but there were no studies attempted to practically apply this corpus for the purpose of student translator training. The current study, has duly attempted to fill this gap and by attempting to apply Arabic-English corpus in the classroom with the view of enhancing students' translation skills as future professional translators. By doing so, we believe that the study has charted the terrain for more future pedagogical studies applying Arabic-English parallel corpora in the translator training and education.

\section{Conclusion}

This is a small-scale qualitative study attempted to explore the potentials of parallel corpus with regard to student translator education and professional development. The study attempted to investigate the translation problems Omani translation major students experience when translating from the source (Arabic) to target (English) language. The aim of the study was to come up with some corpus-informed pedagogy approach for educating and training the students to help them overcome such challenges and generally become better translators. The study first classified the various translation problems based on our experience from teaching those students and also validated them. Students were asked to translate some texts including several problems and then were asked to compare their translations with the mini Arabic-English parallel corpus. They were then interviewed about their views and reflections on the potential benefits that the parallel corpus can provide for them to improve their translation skills and to develop their identity as future professional translators. 
Based on the analysis of the data with regard to the study first research question, it turned out that the participants face a number of challenges when translating from the source (Arabic) to target (English) language. These challenges were observed on both the lexical and grammatical levels. The lexical problems are basically related to the wrong choice of lexical items in the target language, giving the wrong meaning which has been classified into various types: propositional, presupposed and expressive or connotative meaning. Additionally, several grammatical problems were also noticed in the participants' translations, e.g., use of wrong subject- verb agreement, wrong preposition, wrong tense, wrong part of speech, wrong verb form...etc. as was shown above. As for the study second and third research questions, the participants reported that the parallel Arabic-English corpus was helpful and useful as it helped them identify their translation errors so that they could avoid them in the future. In fact, the participants showed an overall positive attitude towards the parallel corpus and they reportedly found it very helpful and promising in improving their translation.

As with the case with any research, there are some limitations that need to be acknowledged. The study was confined to a single context with relatively limited number of participants. Multiple contexts with large number of participants could have provided more insights and perspectives on the issues under investigation. The mini parallel corpus developed by the researchers for the purpose of the present study is very small and ad hoc in nature. The researchers validated, among themselves, the translation of the examples in the mini corpus to ensure the best professional translation accuracy. However, they do not claim that the corpus is perfect. Future studies could expand the scope and design a more professional, comprehensive, representative, typical and computer-processed Arabic-English corpus including various genres and text types to allow for more exploration and solid corpus-based pedagogy. Translation teachers were not involved in the present study but their involvement in future studies could provide another perspective on the opportunities and challenges of the use of corpus-driven approaches for teaching and training student translators. Despite these limitations, we believe that the insights gained from the findings of the present study are illuminating in showing us the potential of parallel corpora in enhancing the training and translation skills of the student translators.

\section{Implications and Recommendations}

In light of the study findings, several recommendations can be made for translation teachers, educators, trainers, translation teaching and materials developers and designers. First, corpus-driven translation pedagogy should be at the heart of translation curriculum reforms and innovation process. Both teachers and students should be made aware of the potential use of corpus-driven approaches for translation teaching and training. Students, as the core element of the translation teaching and learning process, should be made part of any attempt to explore or introduce corpus-driven pedagogy to teaching translation. Second, given the reported potential benefits of the parallel corpus, students should be exposed to more explicit corpus-based translation teaching and training. Teachers could use concordance lines in the classrooms to raise students' awareness about the typical translation challenges and show them how typically professional translators would solve such problems. Third, given the lack of established, welldesigned and multi-generic Arabic-English professional corpora, translation teachers could try and develop their own ad hoc parallel corpus for the purpose of their day-to-day classroom teaching activities. Fourth, translation teachers could also seek out collaboration with other 
colleagues within or outside their educational institution to exchange the good practices in corpus-driven translation teaching. They could also engage into potential research projects for building an Arabic-English parallel corpus for translation teaching and training. Fifth, both translation teachers and students should be trained on the use of corpora in translation and translator education. Students, in particular, need more hands-on training on how to explore and make use of parallel corpora in enhancing their translation skills and generally explore how professional translators would handle various source-to-target language translation problems. Equally, translation teachers should also be trained on the effective use of corpus-driven materials and classroom activities. Sixth, translation course designers and developers should incorporate corpus-driven activities in translation teaching materials and textbooks. Finally, we believe that more communication and coordination is needed among translation teachers, professional translators, translation researchers and translation teaching and training materials developers and designers in order to bridge the gap between research, practice and pedagogy.

\section{About the authors}

Dr. Awad Alhassan is an Assistant Professor of applied linguistics \& TESOL at Dhofar University, Oman. He is also affiliated to Khartoum University in Sudan. He has a PhD in Applied Linguistics from the University of Essex, UK. His teaching and research interests include EAP, corpora in translation \& translator education and English-medium instruction in higher education. He has presented at national and international conferences and published extensively in peer-reviewed journals. ORCID: https://orcid.org/0000-0002-1147-0919

Dr. Yasser Sabtan is an Assistant Professor of Linguistics and Translation at Dhofar University, Oman. He is also affiliated to Al-Azhar University, Egypt. He has a PhD in Computational Linguistics from the University of Manchester, UK. His teaching and research interests include translation studies, corpus linguistics, machine translation, Arabic computational linguistics and EFL. He has presented at several national and international conferences and published extensively in peer- reviewed journals. ORCID: https://orcid.org/0000-0002-4389-285X

Dr. Lamis Omar is an Assistant Professor of Translation and EFL at Dhofar University, Oman. She holds a doctorate in Translation Studies from Durham University, United Kingdom. She taught translation, conference interpreting, EFL and literary criticism at Damascus University, and she also has a long professional experience in English/Arabic translation and conference interpreting. Her research interests include translation and simultaneous interpreting, the conceptual theory of metaphor, Shakespeare's metaphors as well as teaching English as a Foreign Language. ORCID: https://orcid.org/0000-0003-0246-5613

\section{References}

Alhassan, A. (2015). A corpora-driven approach for the Sudanese EFL translation classroom: moving beyond bilingual dictionaries and intuition, $A D A B, 35,31-47$.

Almanna, A. (2016). The Routledge course in translation annotations: Arabic-English-Arabic. London: Routledge Taylor \& Francis Group.

Almanna, A. (2018). The nuts and bolts of Arabic-English translation: An introduction to applied contrastive linguistics. UK: Cambridge Scholars Publishing.

Alotaibi, H. M. (2016). AEPC: Designing an Arabic/English parallel corpus. Research in Corpus Linguistics. 4, 1-7. 
Arab World English Journal (AWEJ) Volume 12. Number 1. March 2021

Alotaibi, H. M. (2017). Arabic-English parallel corpus: A new resource for translation training and language teaching. Arab World English Journal. 8(3), 319-337. DOI: https://dx.doi.org/10.24093/awej/vol8no3.21

Bakari, W., Bellot, P., \&Neji, M. (2016). A preliminary study for building an Arabic corpus of pair questions- Texts from the Web: AQA-Webcorp, iJES, 4(2), 38-45.

Baker, M., (1993). Corpus linguistics and translation studies: Implications and applications. In M. Baker, G. Francis, \& E. Tognini-Bonelli (Eds.), Text and technology: In honour of John Sinclair (pp. 223250). Amsterdam: John Benjamins.

Baker, M. (1995). Corpora in translation studies: An overview and some suggestions for Future research. Target, 7(2). 223-243.

Baker, M. (2018). In other words: A coursebook on translation ( $3^{\text {rd }}$ ed.). London: Routledge Taylor \& Francis Group.

Bell, R. (1991). Translation and Translating: Theory and Practice. England: Longman Group UK Limited.

Bernardini, S., Stewart, D., \& Zanettin, F. (2003). Corpora in translator educa-tion: An introduction. In S. Bernardini, D. Stewart, \& F. Zanettin (Eds.), Corpora in translator education (pp. 1-13). Manchester: St. Jerome.

Bernardini, S. (2004). The Theory Behind the Practice: Translator Training or Translator Education? In K. Malmkjoer (Ed.). Translation in Undergraduate Degree Programmers (pp. 17-29). Amsterdam/Philadelphia. John Benjamins Publishing Co.https://doi.org/10.1075/btl.59.03ber

Biber, D., S. Conrad \& R. Reppen (1998). Corpus Linguistics: Investigating Language Structure and Use. Cambridge: Cambridge University Press.

Bowker, L. (1998). Using specialized monolingual native-language corpora as a translation resource: A pilot study. Meta, 43(4), 631-651. DOI https://doi.org/10.7202/002134ar

Dickins, J., Hervey, S., \& Higgins, I. (2017). Thinking Arabic translation: A course in translation method: Arabic to English (2nd ed.). London: Routledge Taylor \& Francis Group.

Doval, I., \& Nieto, M. T. S. (2019). Parallel corpora in focus: An account of current achievements and challenges, in I. Doval and M. T. Sanchez Nieto eds. (2019). Parallel corpora for contrastive and translation studies: New resources and applications. (pp. 1-38). Amsterdam/Philadelphia: John Benjamins Publishing Company.

Fantinuoli, Claudio, and Federico Zanettin (eds.). 2015. New directions in corpus-based translation studies. Berlin: Language Science Press. DOI: 10.17169/langsci. b76.64

Frankenberg-Garcia, A. (2005). Pedagogical uses of monolingual and parallel concordances. ELT Journal, 59(3), 189-198.

Gabrielatos, C. (2005). Corpora and language teaching: Just a fling, or wedding bells? TESL-EJ, 8(4), 137. http://www.tesl-ej.org/ej32/a1.html

Gallego-Hernández, D. (2015). The use of corpora as translation resources: A study based on a survey of Spanish professional translators, Perspectives, 23(3), 375-391, DOI: $10.1080 / 0907676 X .2014 .964269$

Hareide, L. (2019). Comparable parallel corpora: A critical review of current practices in corpus-based translation studies. In I. Doval, \& M. T. Sanchez Nieto (Eds.), Parallel corpora for contrastive and translation studies: New resources and applications (pp. 19-38). Amsterdam/Philadelphia: John Benjamins Publishing Company.

Jackson, H. (1988). Words and their Meaning. London: Longman.

Jakobson, R. (1959). On linguistic aspects of translation. In L. Venuti (2012), The translation studies reader ( $3^{\text {rd }}$ ed., pp. 126-132), New York and London, Routledge.

Kennedy, G. (2014). An introduction to corpus linguistics ( $2^{\text {nd }}$ ed.). London and New York: Routledge Taylor \& Francis Group. DOI? 
Kenny, D. (2008). Equivalence. In M. Baker, \& G. Saldanha (Eds.), Routledge encyclopedia of translation studies (pp. 96-99). London: Routledge.

Krzeszowski, T. P. (2012). Meaning and Translation: Part 1: Meaning (vol. 7). Lodz: Peter Lang.

Lahlali, E. M., \&Abu Hatab, W. (2014). Advanced English-Arabic translation: A practical guide. Edinburgh University Press.

Marco, J. (2019). Living with Parallel corpora: The Potentials and Limitations of their use. In I. Doval, \& M. T. Sanchez Nieto (Eds.), Parallel Corpora for Contrastive and Translation Studies: New resources and applications (pp. 39-56). Amsterdam/Philadelphia: John Benjamins Publishing Company.

Murphy, L. M. (2010). Lexical meaning. Cambridge: Cambridge University Press.

Newman, D., \&Husni, R. (2015). Arabic-English-Arabic translation: issues and strategies. London: Routledge Taylor \& Francis Group.

Nida, E. A. (1964). Towards a science of translating, Leiden: E. J. Brill.

Nida, E. A., \&Taber, C. R., (1982). The theory and practice of translation. Leiden: E. J. Brill.

O'Hagan, M. (Ed.). (2019). The Routledge handbook of translation and technology. London: Routledge Handbooks.DOI: https://doi.org/10.4324/9781315311258

Olohan, M. (2004) Introducing Corpora in Translation Studies. London and New York: Routledge.

Riemer, N. (2005). The semantics of polysemy: reading meaning in English and Warlpiri. Berlin: Mouton de Gruyter.

Saad, M. K., \&Ashour, W. (2010). OSAC: Open Source Arabic Corpora. EEECS'10 The 6th International Symposium on Electrical and Electronics Engineering and Computer Science, pp. 118-123, European University of Lefke, Cyprus.

Sabtan, Y. M. N. (2016). Bilingual lexicon extraction from Arabic-English parallel corpora with a view to machine translation, Arab World English Journal, special issue on translation, 5, 317-336.

Sinclair, J. M. (Ed.). (2004a). How to use corpora in language teaching. Amsterdam, The Netherlands: John Benjamins.

Van Leuven-Zwart, K. M. (1990): Shifts of meaning in translation: Do's or don'ts? In M. Thelen, \&B. Lewandowska-Tomaszczyk (Eds.), Translation and meaning, Part 1(pp. 226-233). Maastricht: Euroterm.

Varantola, K. (2003). Translators and disposable corpora. In F. Zanettin, S. Bernardini,\& D. Stewart (Eds.), Corpora in translator education (pp. 55-70). Manchester \& Northampton, MA: St. Jerome.

Vinay, J.-P., \&Darbelnet, J. (1995). Comparative stylistics of French and English: A methodology for translation. Amsterdam: John Benjamins.

Yahya, N., Alotaibi, H., \& El-Dakhs, D. A. (2020). Parallel Corpora in EFL Writing Classrooms: Are They Effective? International Journal of Computer-Assisted Language Learning and Teaching, 10 (2), 23-39, DOI: 10.4018/IJCALLT.2020040102

Zanettin, F. (2002). DIY corpora: the WWW and the translator. In B. Maia, J. Haller, \& M. Ulrych (Eds.), Training the language services provider for the new millennium (pp. 239-248). Porto: Universidade do Porto. 